Marshall, J. H. (1960). J. gen. Microbiol. 22, 645-648

\title{
The Production of Anaerobic Conditions with Chromous Salts
}

\author{
BY J. H. MARSHALL \\ Department of Bacteriology, London School of Hygiene and Tropical Medicine, \\ Keppel Street, London, W.C. 1
}

SUMMARY: The absorption of molecular oxygen by chromous salts provides one of the most efficient methods of producing anaerobic conditions. In previous applications to anaerobic culture, hydrogen and chromous ions were produced by the action of sulphuric acid on chromium; chromium metal powder suitable for use in this method is however difficult to obtain. An alternative method of generating hydrogen and chromous sulphate from a mixture of chromic sulphate, zine and sulphuric acid is described. A new indicator of anaerobic conditions which can be used repeatedly is also described.

The use of chromous ions in acid solution as a reagent for the absorption of molecular oxygen was first suggested by Pfordten (1885); it has proved to be one of the most efficient methods of removing oxygen from gas mixtures (Stone, 1936; Stone \& Skavinski, 1945). Rosenthal (1937) applied the method to anaerobic culture, generating hydrogen and chromous ions in a jar by the action of sulphuric acid on chromium metal powder; a modification of this method was described by Mueller \& Miller (1941). The success of Rosenthal's method depends to a large extent on the purity and reactivity of the chromium; the metal must be free from impurities which may produce inhibitory compounds (Smith, 1955) and must react rapidly to produce hydrogen at a rate sufficient to sweep much of the air from the jar. In this country I have been unable to obtain a grade of chromium which meets these requirements.

An alternative method of generating hydrogen and chromous ions is to use a mixture of sulphuric acid, zinc and a chromic salt. Pure granulated zinc is readily available and the hydrogen produced when it reacts with sulphuric acid is much purer than that obtained with commercially available chromium. Trivalent chromium is reduced to the divalent state by zinc and re-oxidized by molecular oxygen; chromium therefore acts as a mediator between zinc and oxygen and oxygen-absorbing capacity will be regenerated until all the zinc has dissolved $\left(\mathrm{Zn}+2 \mathrm{H}^{+}=\mathrm{Zn}^{++}+\mathrm{H}_{2} ; 4 \mathrm{Cr}^{+++}+2 \mathrm{Zn}=4 \mathrm{Cr}^{++}+2 \mathrm{Zn}^{++}\right.$; $4 \mathrm{Cr}^{++}+4 \mathrm{H}^{+}+\mathrm{O}_{2}=4 \mathrm{Cr}^{+++}+2 \mathrm{H}_{2} \mathrm{O}$ ). I have found the modified method more reliable and reproducible than methods which use chromium metal, while retaining the simplicity of Rosenthal's method. No special apparatus or external source of hydrogen is required, simple and cheap jars (e.g. adapted fruit-preserving jars) can be used, provided they are acid-resistant; there is no catalyst or explosion hazard, and oxygen absorbing ability is maintained until all the chromous salt is oxidized. Jars may be set up by the Rosenthal 
method of displacing much of the air by the hydrogen generated, but partial evacuation of the jars is preferable as it ensures more rapid attainment of anaerobic conditions and a larger reserve of oxygen absorbing capacity. The purity of the zinc will influence the rate of evolution of hydrogen, very pure zinc reacting more slowly than less pure material. To ensure a sufficiently rapid rate for the displacement method it may be necessary to activate the zinc with copper (or use commercially available 'zinc activated with copper').

Mueller \& Miller (1941) provided for the production of carbon dioxide in chromium jars by adding sodium carbonate to the reagents. When sodium carbonate was added to the reagents in the present method the reaction was too violent; a much slower and more satisfactory rate of evolution of $\mathrm{CO}_{2}$ was obtained by using calcium carbonate.

\section{METHODS}

Apparatus. Any vessel which can be evacuated and sealed can be used, provided it is not attacked by sulphuric acid. Standard apparatus such as McIntosh and Fildes jars, vacuum desiccators or apparatus designed for use with alkaline pyrogallol such as that of Weinberg \& Schneiter (Weinberg, Nativelle \& Prévot, 1937), can be used, or available apparatus may be adapted. Cheap vessels can be produced from $7 \mathrm{lb}$. Kilner fruit-preserving jars by fitting them with a brass tube through which they can be evacuated. The glass top of the jar is drilled to take the tube which is held in place by a flange below and a screw collar above and sealed by two rubber washers assisted by a little Apiezon vacuum wax (W. Edwards and Co. Ltd., Crawley, Sussex); the rubber ring between the jar and the lid is lubricated with glycerol or some other suitable lubricant. The reagents may be placed in the bottom of the jar and the culture vessels raised, but it is more convenient to place the reagents in a beaker or other suitable dish which should be fitted with a loose fitting cover to trap spray but allow ready diffusion of gas.

Reagents. (1) Pure granulated zinc. Use $3 \cdot 3 \mathrm{~g}$./1. capacity of the jar (2.9 g. will generate $1 \mathrm{l}$. hydrogen at N.T.P.). The McIntosh and Fildes jars I have used have a capacity of $3200 \mathrm{ml}$; t the Kilner jars $2800 \mathrm{ml}$.

(2) Chromic sulphate in $7 \mathrm{~N}$-sulphuric acid. Dissolve $100 \mathrm{~g}$. chromic potassium sulphate $\left(\mathrm{CrK}\left(\mathrm{SO}_{4}\right)_{2} \cdot 12 \mathrm{H}_{2} \mathrm{O}\right.$; chrome alum) in $480 \mathrm{ml}$. water and add $120 \mathrm{ml}$. conc. $\mathrm{H}_{2} \mathrm{SO}_{4}$ (A.R.); when it is necessary to activate the zinc add also $0 \cdot 1 \mathrm{~g}$. $\mathrm{CuSO}_{4} \cdot 5 \mathrm{H}_{2} \mathrm{O}$. Use $20 \mathrm{ml}$. of this solution per litre capacity of jar.

(3) Calcium carbonate (powder). To produce approximately $5 \%(\mathrm{v} / \mathrm{v}) \mathrm{CO}_{2}$, $0 \cdot 23 \mathrm{~g} . \mathrm{CaCO}_{3}$ are needed per litre capacity of jar.

Indicator. The indicator mixture described by Fildes \& McIntosh (1921; methylene blue, glucose, sodium hydroxide) can be used, but it is more convenient to have the indicator in a form which is readily reversible and can be used repeatedly. Stokes (1955) described an indicator of this type 
in which thioglycollic acid is used. I found the following indicator more satisfactory:

$\begin{array}{ll}\text { Methylene blue, 0.04\% (w/v) in 0.2 M-phosphate (pH 7) } & 1.0 \mathrm{ml} \text {. } \\ \text { Ascorbic acid 0.5 \% (w/v) } & 1.0 \mathrm{ml} \text {. } \\ \text { Agar 0.6\% (w/v) } & 8.0 \mathrm{ml} .\end{array}$

(The agar concentration is not critical but should be the minimum which will produce a solid gel.)

First prepare the hot agar solution, then add buffered methylene blue and ascorbic acid; dispense the indicator in $5 \mathrm{ml}$. amounts in $75 \mathrm{~mm} . \times 12 \mathrm{~mm}$. tubes and allow to cool and solidify. In the presence of oxygen a blue zone appears at the surface; under anaerobic conditions the indicator tube becomes colourless. When not in use the tubes should be stoppered to prevent evaporation and to avoid complete oxidation. Should the blue zone extend more than half way down the tube the indicator can be reduced again by heating in a boiling water bath.

Adequate indication of anaerobic conditions is often provided by the pale blue colour of the reduced chromium in ,contrast to the dark green of the oxidized form; the converse is not true, however, as even when most of the chromium is oxidized, the jar may still be anaerobic.

Technique. Place the tubes or plates of cultures in the jar together with an indicator tube, and add the zinc and calcium carbonate to the reagent dish. Then add the chromic sulphate + sulphuric acid solution through a longstemmed funnel, close the jar and evacuate immediately to a residual pressure of 80-100 $\mathrm{mm}$. mercury. Seal the jar and incubate. The jar will have developed a slight positive pressure by the end of the reactions.

Displacement method. Jars may be set up similarly but without evacuation, when desired. The same jars may be used or even containers which will not withstand evacuation, provided they can be sealed. If some form of trap for the escape of gas such as the mercury trap described by Mueller \& Miller (1941) is fitted, the jars can be sealed and incubated immediately after adding the reagents. The amount of air removed by this method will vary considerably according to the design and operation of the apparatus and it is advisable to increase the quantities of reagents by a factor of one and a half over those recommended above, and to use activated zinc. When setting up jars by this technique it should be borne in mind that the gas escaping is a mixture of hydrogen and air.

I should like to thank Mr D. Garwes for his excellent technical assistance.

\section{REFERENCES}

Fildes, P. \& McIntosh, J. (1921). An improved form of McIntosh and Fildes' anaerobic jar. Brit. J. exp. Path. $2,153$.

Mueller, J. H. \& Miller, P. A. (1941). A modification of Rosenthal's chromium-sulfuric acid method for anaerobic cultures. J. biol. Chem. 41, 301. 
Pfordten, O. F. (1885). Neues Absorptionsmittel für Sauerstoff. Liebigs Ann. 228, 112.

Rosenthal, L. (1937). 'Chromium-sulfuric acid' method for anaerobic cultures. J. Bact. 34, 317.

Smith, L. D. (1955). Introduction to the Pathogenic Anaerobes, p. 7. Chicago: University of Chicago Press.

Stokes, E. J. (1955). Clinical Bacteriology, p. 260. London: Arnold.

STONE, H. W. (1936). The use of chromous sulfate in the removal of oxygen from a stream of gas. A comparison with other oxygen absorbents. J. Amer. chem. Soc. 58, 2591.

Stone, H. W. \& Skavinski, E. R. (1945). Quantitative absorption of oxygen. Critical factors in the application of acid-chromous solutions. Industr. Engng Chem. (Anal.), 17, 495.

Weinberg, M., Nativelle, R. \& Prévot, A. R. (1937). Les microbes anaérobies, p. 22. Paris: Masson et Cie.

(Received 16 September 1959) 